\title{
特集 脳動脈瘤の外科治療
}

\section{原 著}

\section{中等度サイズの内頝動脈瘤に対する retrograde suction \& decompression のススメ}

\author{
坪井 俊之, 谷川 緑野, 太田 仲郎, 野田公寿茂, 松川 東俊 \\ 齋藤 寛浩，木下 由宇，宮崎 貴則，井上 靖章，橋本 集 \\ 武田利兵衛，上山 博康，徳田 禎久
}

\section{Recommendation of Retrograde Suction and Decompression for Middle Sized Aneurysms of the Internal Carotid Artery}

Toshiyuki Tsuboi, M.D., Ph.D., Rokuya Tanikawa, M.D., Nakao Ota, M.D., Kosumo Noda, M.D., Hidetoshi Matsukawa, M.D., Norihiro Saito, M.D., Yu Kinoshita, M.D., Takanori MiYazaki, M.D., Yasuaki Inoue, M.D., Atsumu Hashimoto, M.D., Rihei TakedA, M.D., Hiroyasu KamiYama, M.D., and Sadahisa TokUdA, M.D.

Department of Neurosurgery, Sapporo Teishinkai Hospital, Sapporo, Hokkaido, Japan

Summary: The retrograde suction decompression (RSD) technique is highly effective for direct clipping of large or giant intracranial aneurysms (ANs) in the internal carotid artery (ICA) because it can achieve proximal parent vessel control, improve AN neck visualization by shrinking the AN, and help peel off perforating arteries. The purpose of this study was to describe the technique and surgical results of RSD for middle-sized ( $<10 \mathrm{~mm}$ ) AN of the ICA and to recommend the proactive use of RSD for middle-sized ANs of the ICA.

Materials and Methods: We performed clipping of 354 middle-sized $(<10 \mathrm{~mm})$ ANs of the ICA C1-3 portion (ophthalmic and anterior choroidal arteries, posterior communicating artery, and cave) between April 2012 and January 2017. We retrospectively reviewed the clinical data and treatment summaries of 15 cases (4.2\%) treated with RSD-assisted clipping and describe the RSD technique. One male and 14 female patients aged 33-80 years (mean, 58.1 years) were included in the study.

Case Presentation: <Case 1>A 70-year-old-woman with a right internal carotid (IC)-posterior communicating artery AN showed no symptoms. The AN was $8.7 \mathrm{~mm}$ in maximum diameter, projected inferiorly, and preoperative computed tomographic angiography (CTA) revealed no atherosclerosis of the parent vessel. However, during operation, we recognized that the intracranial parent vessel was difficult to secure because of its significant atherosclerosis, the aneurysmal wall was fragile, and the AN was located beneath the tentorial edge. Thus, on the basis of the intraoperative findings, we judged the necessity of the RSD technique for safely freeing the perforating arteries from adhesions.

$<$ Case 2> A 42-year-old woman with an anterior wall AN of the left IC C2 portion showed no symptoms. The AN had a maximum diameter of $6.2 \mathrm{~mm}$. Preoperative CTA and magnetic resonance imaging findings indicated that the left optic nerve was displaced superiorly by the AN. Therefore, before

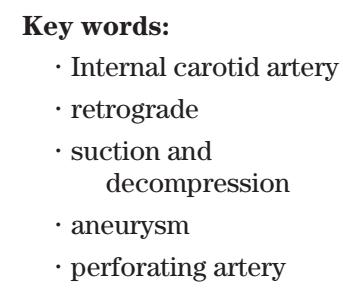

Surg Cereb Stroke

(Jpn) 47: 90-96, 2019 
attempting an approach to the AN, we decided to practice the RSD technique using the preoperative diagnostic images.

Results: All the patients except one had a good outcome, and the neurological finding in one patient was the same as that before operation.

Conclusions: For middle-sized ANs, the RSD technique is a useful procedure to achieve proximal vessel control, to soften and shrink the aneurysmal sac, and to provide a wide and clean operative field that allows for a safe clip placement. During operation, we confidently recommend performing the RSD technique for safely freeing perforating arteries from adhesions to the fragile aneurysmal wall, except for small ANs.

\section{はじめに}

頭蓋内大型，巨大内䅡動脈瘤において， retrograde suction and decompression method(RSD) はきわめて有効で ある ${ }^{1-3) 6)}$ 。その理由は, 頚部内頝動脈において中枢確保 が可能となること, mass として存在する動脈瘤の内圧を 減じて縮小させることで術野確保が可能となること, それ により, 動脈瘤と穿通枝, 周囲正常構造物 (特に傍床突起 動脈瘤における視神経圧迫など) との癒着を安全に剥離可 能となるからである。これらの有効性に加えて, RSDの ための cannulation 操作手技自体も簡便であることから, われわれは, $10 \mathrm{~mm}$ 未満の中等度サイズの内頝動脈瘤に 対しても，より積極的に併用すべきであると考える.

本稿では, $10 \mathrm{~mm}$ 未満の中等度サイズの内頝動脈瘤に 対してわれわれが行っている上甲状腺動脈からの RSD の 手技を紹介し, 術中における注意点についても考察し報告 する。

\section{対象}

2012 年 4 月 1 日から 2017 年 1 月 31 日の間に当院にて 治療を行った脳動脈瘤(破裂, 未破裂含む) 1,134 例中, 動 脈瘤の最大径が $10 \mathrm{~mm}$ 未満である内頚動脈 C1-3 部 (眼動 脈, 前脈絡叢動脈, 後交通動脈分岐部, Cave 動脈瘤)の動 脈瘤 354 例のうち RSD を施行した 15 症例を対象とした。 上記の対象症例について, 当施設で行っている RSD の手 技の実際とその成績について報告し，また，RSDの適応 について検討した.

\section{方法}

\section{RSD の手技の実際}

当施設では, 内頚動脈瘤に対する開頭 clipping 術の場 合には，常に術側の䅡部䅡動脈を清潔野に含めるようにし ている，術中，予期せず頚部での中枢確保が必要となった 場合，躊躇なく迅速に対応 (最悪でも経皮的に用手圧迫が 可能)できるからである。

cannulation tube は, ATOM tubeの $4 \mathrm{Fr}$, ないし $5 \mathrm{Fr}$ feeding tube を使用する(Fig. 1A)。頚部で総頚動脈, 内頝
動脈，外頚動脈，上甲状腺動脈を露出した後，上甲状腺動 脈の起始部に temporary clip をかけ, cannulation 可能な 長さを確保したらその遠位部を絹糸などで結紮，動脈壁を T-shapedに切開し, 内膜の解離を生じないよう注意して cannulationする(Fig. 1B)， tube の先端が，外頚動脈から 総澒動脈に向かって確実に挿入されるよう guideする(Fig 2). suction and decompression の操作時に, 外頚動脈, 総䅡動脈を血管鉗子などで一時遮断するが, tube の㨂入 が長すぎると，その際誤って ATOM tube を一緒に遮断す る可能性があるので注意が必要である， $2,3 \mathrm{~cm}$ 程度挿入 されていれば十分である. cannulation 後は， tube 内が閉 塞しないようへパリン加生理食塩水を充満させておく.

cannulation 時に, 上甲状腺動脈の血管径に比して ATOM tube のサイズが大きすぎる場合，上甲状腺動脈が 内膜解離を起こして挿入困難となることがあるが，その場 合は，外澒動脈を直接穿刺することで同様の効果が得られ る.

\section{2. 一時遮断時の閉塞時間}

当院では, 1 回あたりの遮断時間は, 10 分以内を目安に している。遮断中の motor evoked potential(MEP) モニ ターの低下の有無にかかわらず遮断解除後は脳虚血からの 回復のため, 次の遮断の前に少なくとも 5 分以上の間隔を 設けるようにしている.

\section{結 果}

RSD を併用した症例は全 15 例 (4.2\%), 性別は男性 1 例, 女性 14 例, 年齢は 33-80 歳 (平均 58.1 歳), 動脈瘤の サイズは 6.4-9.6 mm(平均 $8.3 \mathrm{~mm}$ ) であった. 14 例が未破 裂動脈瘤， 1 例が破裂動脈㽣であった。追加の手技として, 前床突起削除は 7 例, superficial temporal artery (STA)middle cerebral artery (MCA) bypass carotid artery (ECA) -saphenous vein graft (SVG)-M2 bypass が 1 例であった. 3 力月後の機能予後は, modified Rankin Scale (mRS) 0 が 13 例, mRS 1 が1例であった. mRS 2 の 1 例は, 術前後で増悪を認めなかった.

15 症例の patient characteristics を Table 1 へ示す. 

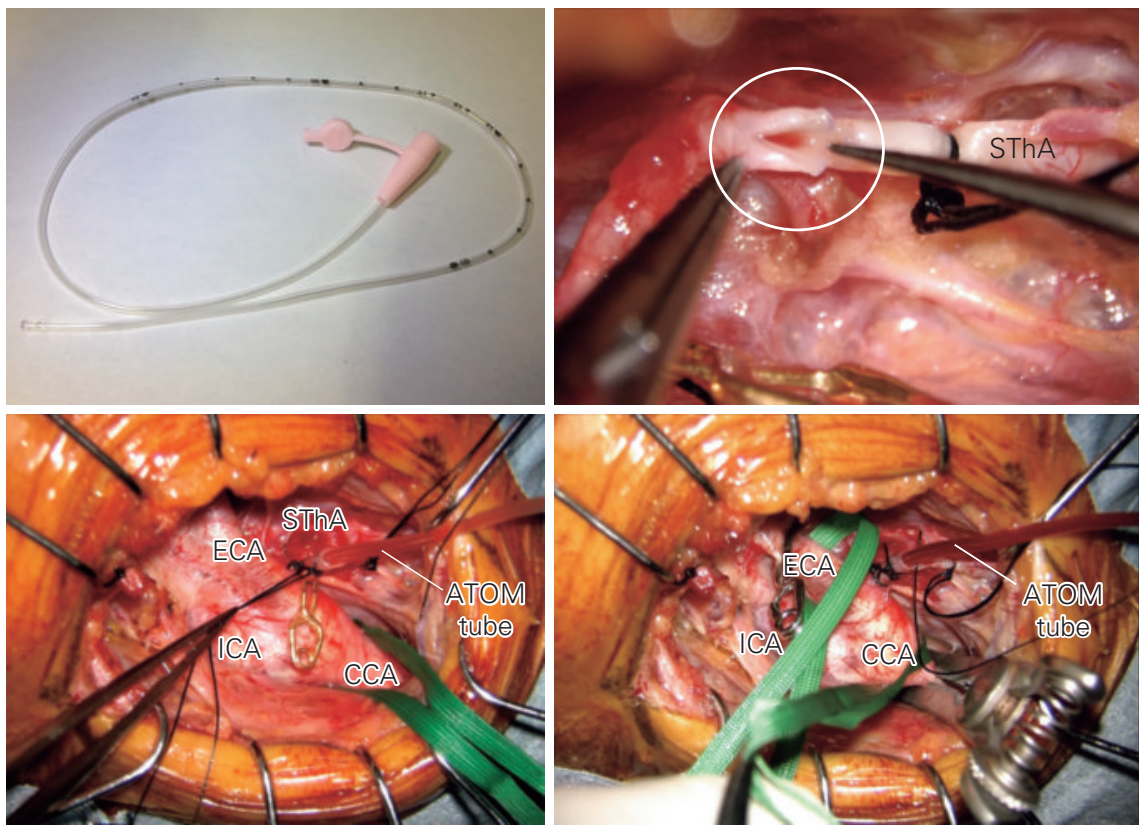

Fig. 1 Retrograde suction decompression (RSD).

\begin{tabular}{l|l} 
A & B \\
\hline C & D
\end{tabular}

A: A 5-Fr Atom feeding tube.

B: The superior thyroid artery (SThA) is trimmed into the T-shaped incision.

C: Cannulation into the SThA.

D: RSD is just about to be performed. The intra-aneurysmal blood flow is aspirated from the cannulation into the SThA when the external carotid artery (ECA) and common carotid arteries (CCA) are cut off.

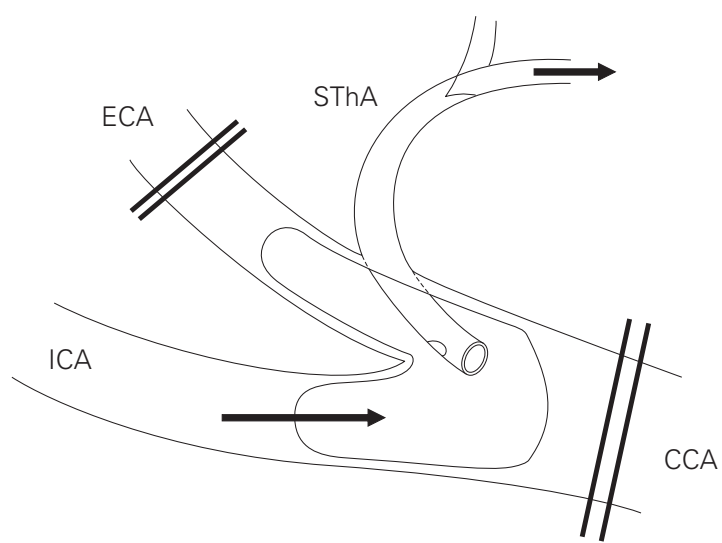

Fig. 2 Retrograde suction decompression (RSD).

The front edge of the cannulation into the superior thyroid artery (SThA) is located at the common carotid artery (CCA).

ECA: external carotid artery, ICA: internal carotid artery

\section{$10 \mathrm{~mm}$ 未満の脳動脈瘤に対する RSD の適応}

RSD が必要であると判断したタイミングとその根拠に ついて検討する.

術前検討の段階であらかじめ準備が必要であると判断し たのは, 354 例中 11 例 (3.1\%, 破裂例, previous treated coil embolization, C1，C2 動脈瘤)であり，その判断の根
拠は以下である.

・破裂例であり, 後交通動脈とその穿通枝との高度な癒着 が予想され，頚部での中枢確保も併施できるため

- C2 部動脈瘤：視神経への圧排が著明であり, 術操作に よる視神経障害の悪化を防止する目的

- $\mathrm{C} 1$ 部動脈瘤: 術前画像診断で, posterior communicating $\operatorname{artery}(\mathrm{PcomA})$, 前視床穿通動脈 (anterior thalamoperforating artery: AThPA), 前脈絡叢動脈 (anterior choroidal artery：AchA), 動眼神経のそれぞれと動脈 瘤が癒着して抢り，テント下に埋没している所見を認め たうえ，さらに，母血管の高度動脈硬化を示す所見を認 めたため, 頭蓋内での中枢確保が困難と予想された

上記の 11 例で，あらかじめ準備しておいた RSD が術中 に不要であった症例はなく, 全例で使用し有用であった。

一方，あらかじめ準備せず，術中所見により RSD が必 要と判断したのは 4 例 (1.1\%, 全例 $\mathrm{C} 1$, Pcom 分岐部)で, その判断根拠は, 以下である.

(1)母動脈の動脈硬化が高度で, 一時遮断により, 母血管の 動脈解離が危惧された

(2)動脈瘤壁がきわめて菲薄で, tentorial edge 下に埋没し ており，穿通枝，動眼神経と癒着していた

(1)の理由のみであれば, 頚部での中枢確保だけで十分 
Table 1 Summary of patient characteristics

\begin{tabular}{|c|c|c|c|c|c|c|c|c|c|c|c|}
\hline Case & Age & Sex & Location & $\begin{array}{l}\text { Size } \\
(\mathrm{mm})\end{array}$ & $\begin{array}{l}\text { Additional } \\
\text { procedure }\end{array}$ & $\begin{array}{l}\text { Clinoid- } \\
\text { ectomy }\end{array}$ & $\begin{array}{l}\text { Site of tempo- } \\
\text { rary clipping }\end{array}$ & $\begin{array}{l}\text { Time of ICA } \\
\text { occlusion }\end{array}$ & $\begin{array}{l}\text { Cerebral } \\
\text { ischemia }\end{array}$ & Symptoms & $\begin{array}{c}\text { mRS } \\
(3 \mathrm{mon} .)\end{array}$ \\
\hline$* 1$ & 71 & $M$ & Rt.IC-PC & 8.6 & - & - & C1, Pcom & $8^{\prime} 48$ & - & - & 0 \\
\hline 2 & 52 & $F$ & SAH, Lt.IC-PC & 9.6 & STA-MCA & - & C1, Pcom & $8^{\prime} 57$ & - & - & 0 \\
\hline$* 3$ & 70 & $\mathrm{~F}$ & Rt.IC-PC & 8.7 & - & - & C1 & $6^{\prime} 01$ & - & - & 0 \\
\hline 4 & 33 & $F$ & Rt.C2 & 9.6 & - & + & C2 & $2^{\prime} 22$ & - & $\begin{array}{l}\text { Oculomotor } \\
\text { palsy }\end{array}$ & 1 \\
\hline 5 & 46 & F & Lt.C2 & 7.6 & STA-MCA & + & C2, oph & 7'57 & - & - & 0 \\
\hline 6 & 56 & $F$ & Lt.C2 & 8.7 & $\begin{array}{l}\text { STA-MCA, } \\
\text { EC-SVG-M2 }\end{array}$ & + & C2 & 3'34 & - & $\begin{array}{l}\text { Same as } \\
\text { preope }\end{array}$ & 2 \\
\hline 7 & 66 & $\mathrm{~F}$ & Rt.C2 & 8.2 & - & + & $\mathrm{C} 2$ & $8^{\prime} 32$ & - & - & 0 \\
\hline *8 & 70 & $\mathrm{~F}$ & Rt.IC-PC & 8.7 & - & - & $\mathrm{C} 1$ & $5^{\prime} 58$ & - & - & 0 \\
\hline 9 & 80 & $\mathrm{~F}$ & Rt.IC-PC, coil & 8.1 & - & - & $\mathrm{C} 1$ & $8^{\prime} 45$ & - & - & 0 \\
\hline 10 & 48 & $F$ & Rt.IC-Cave & 6.4 & - & + & C2, oph & $6^{\prime} 41$ & - & - & 0 \\
\hline 11 & 63 & $\mathrm{~F}$ & Rt.IC-PC & 8.8 & - & - & C1, Pcom & $11 ' 30$ & - & - & 0 \\
\hline 12 & 42 & $\mathrm{~F}$ & Lt.C2 & 6.5 & - & + & $\mathrm{C} 2$ & $18^{\prime} 56$ & - & - & 0 \\
\hline 13 & 59 & $\mathrm{~F}$ & SAH, Rt.IC-PC & 9 & - & - & $\mathrm{C} 1$ & $14^{\prime} 45$ & - & - & 0 \\
\hline 14 & 42 & $F$ & Rt.C2 & 6.6 & - & + & C2 & $13^{\prime} 36$ & - & - & 0 \\
\hline$* 15$ & 73 & $\mathrm{~F}$ & Lt.IC-PC & 9.6 & - & - & C1 & $6^{\prime} 09$ & AThPa & $\begin{array}{c}\text { Cognitive } \\
\text { dysfunction }\end{array}$ & 0 \\
\hline
\end{tabular}

M: male, F: femal, Rt.: right, Lt.: left, IC-PC: internal carotid-posterior communicating artery, C1: C1 portion of the internal carotid artery, Pcom: posterior communicating artery, C2: C2 portion of the internal carotid artery, SAH: subarachnoid hemorrhage, STA: superficial temporal artery, MCA: middle cerebral artery, oph: opthalmic artery, EC-SVG-M2: external caroitid artery-saphenous vein graft-M2 bypass, AThPA: anterior thalamoperforating artery, preope: preoperative state

* Cases judged to require RSD during an operation. Bold face: representative cases

で, RSD は不要である可能性も考えられるが，瘤壁がき わめて菲薄であり, 瘤内圧を減じることなく剥離操作を行 えば，瘤壁の菲薄化と母血管の動脈硬化との discrepancy により，予期せず neck laceration が生じることが危惧さ れたため, RSD を施行した.

RSD の際の上甲状腺動脈への cannulation 操作に伴う合 併症は認めなかった.

\section{症例}

〈症例 1〉Case 3(Fig. 3)

術中所見で RSD が必要と判断した症例

70 歳, 女性.

無症候, 右内頚動脈-後交通動脈分岐部動脈瘤.

術前画像所見: 動脈瘤は, 最大径 $8.7 \mathrm{~mm}$, 下向きで内 䅡動脈海綿静脈洞部に接していると予想された。母血管の 動脈硬化を強く示唆する所見は認めなかった.

術中所見：母血管の動脈硬化がきわめて高度であり, 頭 蓋内での中枢確保が困難, 瘤壁もきわめて菲薄であり, 瘤 がテント下に埋没していた，安全にテントから剝離を行う ため, 頚部での中枢確保と瘤内圧減少を目的として RSD を施行した。

動脈瘤の遠位部を一時遮断し, RSD 施行, 瘤内圧を減
弱させテントから剝離し, neck clipping を完遂した。indocyanine green(ICG) ですべての穿通枝の描出を確認 し，手術を終了した。

術後：神経学的異常所見を認めず, mRS 0 で独歩退院し た。

〈症例 2〉 Case 12 (Fig. 4)

\section{あらかじめ RSD を準備した症例}

42 歳, 女性。

無症候, 左内澒動脈 $\mathrm{C} 2$ 部前壁動脈瘤.

術前画像所見：動脈瘤は, 内澒動脈 $\mathrm{C} 2$ 部前壁上向き で, 最大径 $6.2 \mathrm{~mm}$ であった，動脈瘤が視神経を外側から 圧排していると予想された。視神経の保護, 動脈瘤と視神 経の安全な剥離, 中枢確保の目的で, 開頭に先立ちあらか じめ RSDの準備を行った.

術中所見：前床突起削除後, 硬膜切開すると, 術前画像 所見のごとく，動脈瘤が視神経を外側から圧排していた。 瘤壁は菲薄であったが，母血管に動脈硬化は認めなかっ た，RSD を施行し，瘤内圧を減弱させ，動脈瘤と視神経 を剥離し, neck clipping を完遂した。術中 visual evoked potential(VEP) monitor，ICG ともに異常は認めず，手術 を終了した。 

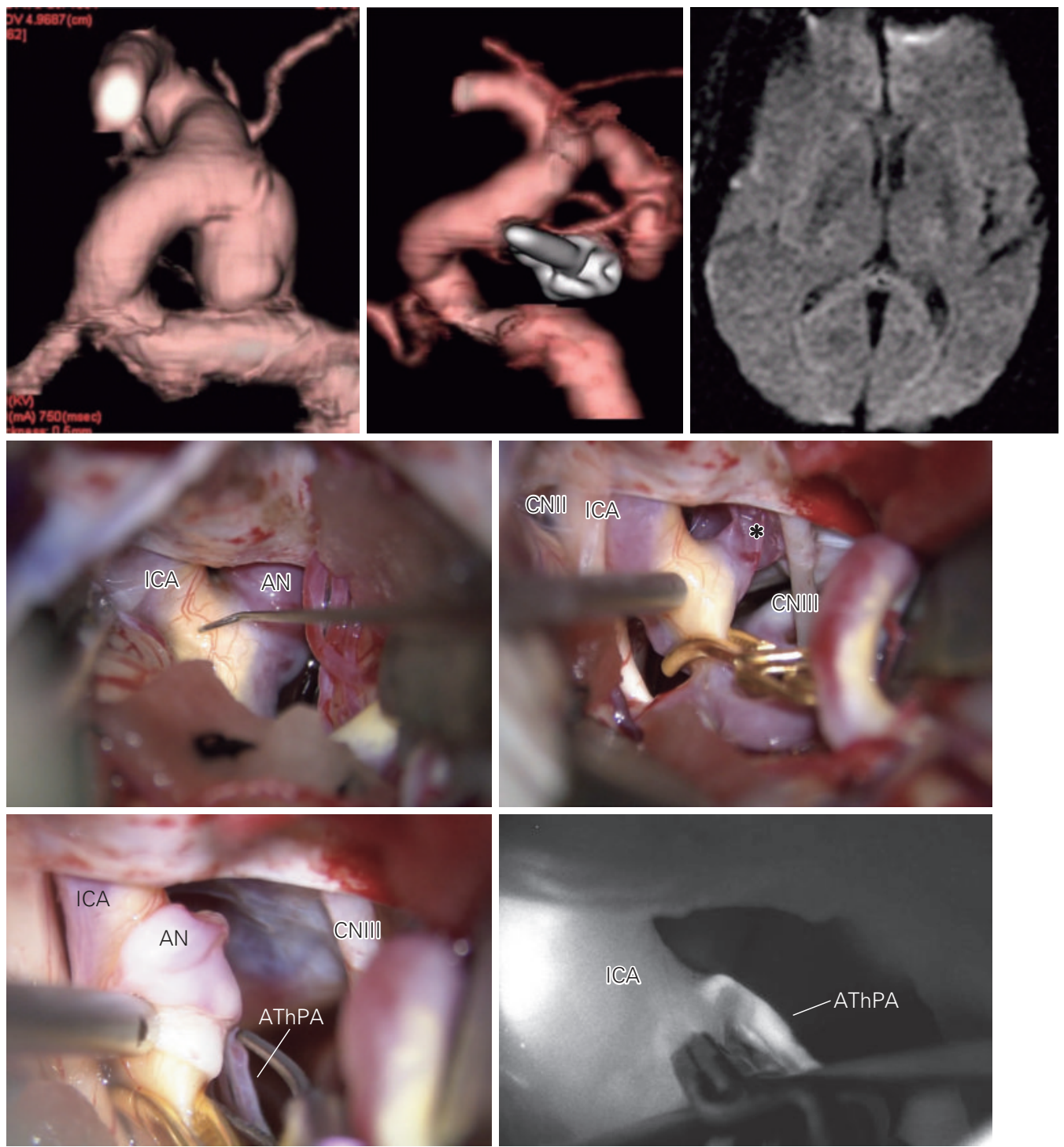

A1 $\mid$ A2 $\mid$ A3

Fig. 3 Case 1:

\begin{tabular}{l|l}
\hline B & C \\
\hline D & E
\end{tabular}

A case of right internal carotid-posterior communicating artery (IC-PC) aneurysm (AN) in a 70-year-old woman.

A: Preoperative and postoperative three-dimensional computed tomographic angiography (CTA) and magnetic resonance imaging (MRI) scans.

A1: Preoperative CTA image showing the IC-PC aneurysm of $8.7 \mathrm{~mm}$ in maximum diameter. A2: Postoperative CTA image: The IC-PC aneurysm is not demonstrated, but the posterior communicating artery (PcomA) and its perforating arteries are clearly visible.

A3: Postoperative MRI scan: No hyperintensity signal can be observed on the diffusionweighted image (DWI).

B-E: Intraoperative findings.

B: The parent vessel had a significant atherosclerosis, so we could secure the parent vessel in the intracranial space and locate the aneurysm beneath the tentorial edge.

C: Right before performing the retrograde suction decompression (RSD) technique. The aneurysm shrinks and attaches to the oculomotor nerve.

* Shrunk aneurysm

D: Neck clipping of the aneurysm shrank using the RSD technique. The anterior thalamoperforating arteries (AThPAs) arising from the PcomA is plainly visible.

E: Indocyanine green (ICG) videography demonstrating the AThPAs.

CNIII: oculomotor nerve 

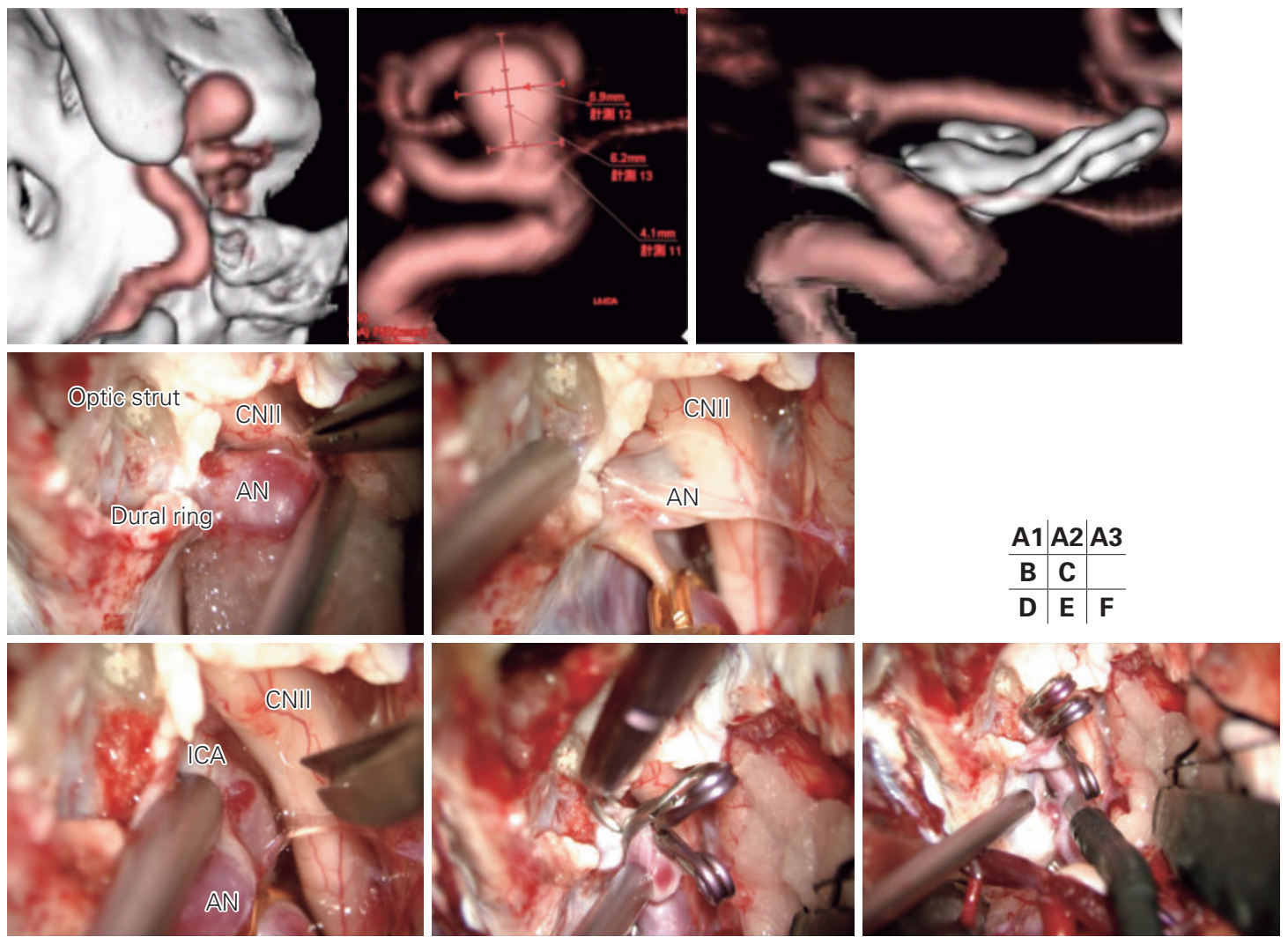

Fig. 4 Case 2:

A case of anterior wall aneurysm (AN) of the left internal carotid (IC) C2 portion in a 42-year-old woman.

A: Preoperative and postoperative computed tomographic angiography (CTA) images.

A1: The left optic nerve is speculated to be displaced superiorly by the AN.

A2: Preoperative CTA image showing an IC-posterior communicating artery (PC) AN of $6.2 \mathrm{~mm}$ in maximum diameter.

A3: Postoperative CTA image showing no AN but clearly indicating the ophthalmic artery.

B-F: Intraoperative findings.

B: The left optic nerve displaced superiorly by the AN.

C: The retrograde suction decompression (RSD) technique is just about to be performed. The AN is shrunk and peeled from the left optic nerve easily.

D: The AN is recanalized after the RSD technique. The micro bleb is identified near the neck of AN.

E: The AN is occluded with multiple clips.

F: Final view after complete neck clipping. The Doppler blood flow measurement values are normal.

術後：神経学的異常所見を認めず, mRS 0 で独歩退院し た.

RSD を併用した 15 症例の summary は Table 1 を参照.

\section{考察}

\section{RSD の適応について}

当施設に打いて, 動脈瘤 clipping 術の基本方針として, 動脈瘤内圧の減弱が必要な場合, 頭蓋内, または頚部での 内頚動脈一時遮断を第一選択としている。母血管の動脈硬 化が高度な場合, 動脈㽣の massによる視神経圧迫が著し い場合, 動脈瘤壁が高度に菲薄化している場合などにおい て, 動脈瘤との癒着剝離を安全に施行し得る方法として,
RSD が適切であると判断した際に, RSD を併用している. この適応に沿って RSD を併用した対象症例は，354 例中 15 例 ( $4.2 \%)$ である.

\section{RSD 施行時の注意点と trouble shooting 1) 実際の suction 時の注意点}

上記の手順に沿って RSD の準備が整い，いざ suction \& decompression を行うが, 吸引に使用するシリンジは, $10 \mathrm{ml}$ 程度の容量で十分である. 助手は術野を確認しなが ら，小さな strokeでシリンジの吸引を行うが，急激な動 脈瘤内圧の変動をきたさないよう注意が必要である，動脈 瘤と癒着している視神経, 穿通枝などの構造物を損傷する 
危険性があり，また，予期せ好破裂，neck lacerationの原 因になりかねないからである。

また，吸引により動脈瘤内圧が減圧され，正常構造物と の癒着が剝離でき, いざ clipping 術施行の際には closure line を確認するため, ヘパリン加生理食塩水を注入して動 脈瘤を膨張させる操作が必要な場合がある。このときも術 者の指示に従い, 急激な動脈瘤内圧の変動をきたさないよ う繊細なシリンジ操作が要求される.

\section{2) trouble shooting}

suction を実行しても思うように動脈瘤内压の減圧が期 待できない場合, 以下のような事態が想定される.

(1) suction できない: ヘパリン加生理食塩水の注入は可能 であるが，吸引できない場合 cannulation tube の挿入が長 すぎるため, tube 先端が血管壁に干渉している，また は, 総䅡動脈の遮断時に tube ごと挟んでいる状態などが 想定される．抻入部を短くすることで解決する.

(2) suction し続ける:多くの場合, 眼動脈からの逆流が考 えられる. また, 後交通動脈, 母血管の遠位部遮断が不十 分な状態も想定されるため, 遮断の状態を再確認する.

\section{3. assist bypass 併用の適応について}

術前, もしくは術中判断で, 穿通枝と動脈瘤の癒着など の剝離操作に際して 1 回あたりの遮断時間が 10 分以上を 要すると判断した際には, STA-MCA bypass(場合によ り，ECA-M2 bypassのこともあり)を作成することとし ている.

assist bypass の有用性について, RSD を併用すること なく, 内頚動脈系の一時遮断のみで動脈瘤処理が可能な場 合においては一時遮断中の脳虚血対策には有用である。し かし， RSD を併用した症例においては, 総澒, 外頚動脈 が一時遮断されているため, 外澒動脈系を利用したbypass は一時遮断中の脳虚血対策には無効である。

今回の 15 症例中 3 例において, assist bypass を併用し ているが，この目的は RSD 施行中の虚血対策ではなく， 母血管の動脈硬化が高度であり, 操作中に neck laceration などが生じて trapping となる可能性が懸念されたため, その際の皮質領域の虚血対策として併用したものである.

C1 部動脈瘤に対して suction \& decompression method を用いた治療成績についての報告はほとんどなく,さら に, 大型, 巨大脳動脈瘤を対象としたもののみである ${ }^{1)-315)}$.

大型, 巨大 $\mathrm{Cl}$ 部動脈瘤は, 術後穿通枝障害の頻度が高 いとの報告 ${ }^{4)}$ があるが, その要因として, 穿通枝の盲端化, 動脈瘤の瘾着した穿通枝の剝離操作による vasospasm, 穿通枝の長時間の遮断が挙げられている。動脈瘤サイズと 穿通枝の癒着の程度が比例する傾向にあり，穿通枝の確認 と安全な剥離を行うための広い working space を確保する
手段として, suction \& decompression は有用であるとさ れている゙่.

今回, われわれが対象としたのは $10 \mathrm{~mm}$ 未満の中等度 サイズの動脈瘤であり, 広い術野確保という観点において はRSD の有用性は薄いと考えられる。しかし，母血管の 高度動脈硬化と動脈瘤壁の菲薄化との discrepancy が存在 する状態で穿通枝剝離操作を行えば, 動脈瘤 neckに過剩 な力が加わり neck laceration が生じることが危惧され る.今回のわれわれの報告でも, 実際にRSDを併用し, 動脈瘤内圧を減じた状態での穿通枝剥離操作はきわめて有 効であり, 症候性となった穿通枝障害は皆無であった。

穿通枝の虚血障害は, STA-MCA bypass な゙゙の assist bypass では回避できず，たとえ小型サイズの動脈瘤でも 穿通枝剝離に長時間を要すれば起こり得るため, 動脈瘤サ イズによってRSDの適応は決定できないと考えられる.

「菲薄化した瘤壁に打ける安全な穿通枝剥離」という観点 においては, 中等度サイズの動脈瘤に対する RSD は, き わめて有用であると考える。

\section{結語}

$10 \mathrm{~mm}$ 未満の中等度サイズの内䅡動脈瘤に対する retrograde suction \& decompression の有用性を報告した。

RSD は, 一概に動脈瘤サイズによるのではなく, 菲薄 化した瘤壁に対して安全に癒着剝離が可能と判断した際に は，「その一手間」を惜しむことなく，追加の手技として 積極的に併用すべきと考える.

本論文の要旨は STROKE2017 第 46 回日本脳卒中の外科 学会 (2017 年 3 月, 大阪)に抒いて発表した.

\section{文献}

1) Chen, SF, Kato Y, Subramanian B, et al: Retrograde suction decompression assisted clipping of large and giant cerebral aneurysms: our experience. Minim Invasive Neurosurg 54: $1-4,2011$

2) Eliava SS, Filatov YM, Yakovlev SB, et al: Results of microsurgical treatment of large and giant ICA aneurysms using the retrograde suction decompression (RSD) technique: series of 92 patients. World Neurosurg 73: 683-687, 2010

3) Otani N, Wada K, Toyooka T, et al: Usefulness of suction decompression method combined with extradural temporopolar approach during clipping of complicated internal carotid artery aneurysm. World Neurosurg 90: 293-299, 2016

4) Takebayashi S, Kamiyama H, Takizawa K, et al: The significance of intraoperative monitoring of muscle motor evoked potentials during unruptured large and giant cerebral aneurysm surgery. Neurol Med Chir (Tokyo) 54: 180-188, 2014

5) Takeuchi S, Tanikawa R, Goehre F, et al: Retrograde suction decompression for clip occlusion of internal carotid artery communicating segment aneurysms. World Neurosurg 89: 1925, 2016 